\title{
Cryptogenic ischemic stroke and silent atrial fibrillation: What is the relationship?
}

Mustafa Karaca' ${ }^{*}$, D. Aytekin², T. Kırıs ${ }^{1}$, A. Koskderelioglu³ and M. Gedizlioglu ${ }^{3}$

\begin{abstract}
Atrial fibrillation (AF) is responsible for up to one-third of ischemic strokes and associated with silent cerebral infarctions and transient ischemic attacks. Any method that predicts the stroke or unmasks the silent PAF would contribute to the treatment of ischemic stroke. Intraatrial conduction time (ICT) has been shown to be associated with intermittent AF. In this study, we evaluated the value of ICT detected by transthoracic echocardiography in normal population and in patients with cryptogenic stroke (CS) as a risk factor for stroke. The patients with CS and with normal left ventricular function without valvular disease are included in group 1. Patients with atypical symptoms admitted to cardiology clinics without any risk factor for cardiac disease and found to be normal constituted group 2. Age, gender, weight, height, echocardiographic parameters and ICT were compared between groups. 63 and 64 subjects were included in group 1 and 2, respectively. Two groups were similar according to age and gender. Among the parameters studied, left atrial diameter and height of the patients were significantly higher in group 1 (40 \pm 2 vs $37 \pm 4 \mathrm{~mm}$, $p<0.001$ and $167 \pm 9$ vs $163 \pm 9 \mathrm{~cm} \mathrm{p}=0.027$, respectively). ICT was significantly higher in group 1 (131 $\pm 15 \mathrm{vs}$ $118 \pm 13 \mathrm{~ms}$, respectively, $\mathrm{p}<0.000$ ). According to ROC analysis, a cut point of $124 \mathrm{~ms}$ for ICT with a sensitivity of $74 \%$ and specificity of $73 \%$ in patients with CS $(p<0.001)$. This study show us, the measurements the ICT determined by means of echocardiography is longer in patients with CS. This simple and noninvasive technique can be applied widely and lead the clinicians to adopt the use of diagnostic and the treatment procedures.
\end{abstract}

Keywords: Atrial fibrillation, Cryptogenic stroke, Intraatrial conduction time, Echocardiography

\section{Background}

Atrial fibrillation (AF) is responsible for up to one-third of ischemic strokes and associated with silent cerebral infarctions and transient ischemic attacks (TIA; Mohr 1988). The self-terminating and often asymptomatic nature of paroxysmal AF may lead to its underdiagnoses. We suggest that a significant proportion of the unexplained strokes or TIA can be due to undiagnosed AF (Sanna et al. 2014). Any method that predicts the stroke or unmasks the silent AF would contribute to the treatment of ischemic stroke. Intraatrial conduction time (ICT) has been shown to be associated with intermittent AF (Kinay et al. 2002). Intraatrial conduction time is commonly measured by invasive electrophysiological

\footnotetext{
*Correspondence: mustafakaraca99@hotmail.com

1 Atatürk Ĕğitim Araştırma Hastanesi Kardiyoloji Bölümü, Basın Sitesi

35150 Karabağlar, Izmir, Turkey

Full list of author information is available at the end of the article
}

methods, and this measurement shows congruity with non-invasive echocardiographic calculation (Karaca et al. 2007). In this study, we aimed to investigate the value of ICT in the normal population and cryptogenic stroke (CS) patients by using the noninvasive method of transthoracic echocardiography (TTE).

\section{Results and discussion}

Groups 1 and 2 were constituted of 63 and 64 subjects, respectively. Baseline characteristics and ICT measurement of the study population are presented in Table 1 . The two groups were similar according to age and gender. Among the parameters studied, left atrial diameter and height of the patients were significantly higher in group $1(40 \pm 2$ vs $37 \pm 4 \mathrm{~mm}, \mathrm{p}<0.001$ and $167 \pm 9$ vs $163 \pm 9 \mathrm{~cm} \mathrm{p}=0.027$, respectively). ICT was significantly longer in group $1(131 \pm 16$ vs $118 \pm 13 \mathrm{~ms}$, respectively, $\mathrm{p}<0.000)$.

\section{贷 Springer}

(c) 2016 Karaca et al. This article is distributed under the terms of the Creative Commons Attribution 4.0 International License (http://creativecommons.org/licenses/by/4.0/), which permits unrestricted use, distribution, and reproduction in any medium, provided you give appropriate credit to the original author(s) and the source, provide a link to the Creative Commons license, and indicate if changes were made. 
Table 1 Baseline characteristics and ICT measurement of the study population

\begin{tabular}{llll}
\hline Variables & Group 1 $(\mathbf{n = 6 3})$ & Group 2 $(\mathbf{n = 6 4 )}$ & p value \\
\hline Age, years & $62 \pm 10$ & $62 \pm 9$ & NS \\
Male/female & $38 / 26$ & $39 / 24$ & NS \\
Height, cm & $167 \pm 9$ & $163 \pm 9$ & 0.027 \\
Weight, kg & $75 \pm 1$ & $76 \pm 1$ & NS \\
LA dimension & $40 \pm 2$ & $37 \pm 4$ & $<0.001$ \\
EF & 57.2 & 58.5 & NS \\
ICT & $131 \pm 15$ & $118 \pm 13$ & $<0.000$ \\
\hline
\end{tabular}

EF ejection fraction, ICT intraatrial conduction time, $L A$ left atrium

In the present study, we found that ICT was prolonged in patients with CS compared with healthy subjects (group 1 vs group $2 ; 131 \pm 15$ vs $118 \pm 13 \mathrm{~ms}, \mathrm{p}<0.000$ ). According to ROC analysis, a cut point of $124 \mathrm{~ms}$ for ICT identified the patients at risk of CS with a sensitivity of $74 \%$ and specificity of $73 \%(\mathrm{p}<0.001$, Fig. 1$)$.

Cryptogenic stroke has a devastating clinical outcome. Its cause is unknown even after vigorous neurological, radiological and other laboratory evaluation. It is well established that the presence of AF is associated with an almost fivefold increased risk of stroke (Wolf et al. 1991). Silent AF and other cardiac sources may be partly responsible for $\mathrm{CS}$ and yet still difficult to disclose. Other risk factors related to stroke and silent AF may be value for the approach to this patient population.

The prolongation of ICT and inhomogeneous propagation of sinus impulses are well known electrophysiological

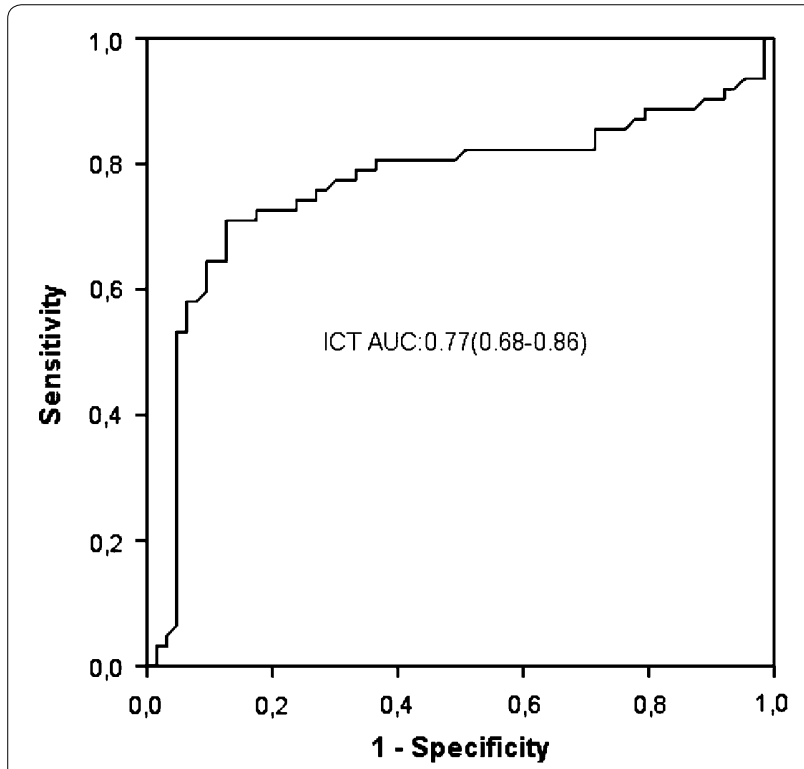

Fig. 1 Receiver operating curve of intraatrial conduction time for cryptogenic stroke characteristics in patients with AF (Villani et al. 1996; Dogan et al. 2012). Subclinical atrial dilatation may be the cause and substrate of decremental conduction properties which may lead to inducible episodes of AF (Cozma et al. 2006).

Intraatrial conduction time can be determined invasively in the EP lab. A previous study by our group has shown that there was a significant correlation between ICT measurement determined by transesophageal echocardiography and invasive electrophysiological study (Karaca et al. 2007). A limited number of studies have revealed increased episodes of AF in patients with prolonged ICT. Another study has reported that this method predicted AF in patients with a long ICT detected during open heart surgery following coronary by pass operation (Karaca et al. 2012). TEE was, however, found to be a useful tool for measuring ICT. There is a significant association between ICT and recurrence of AF (Kinay et al. 2002). In a previous study, investigators simultaneously measured the time interval between the electrocardiographic P wave and the mitral "a" wave using transthoracic Doppler echocardiography, and they compared this noninvasive ICT measurement with the invasive method (Fuenmayor et al. 2002). They concluded that transthoracic Doppler echocardiography combined with surface electrocardiography could be used for measuring the ICT with a similar accuracy as other more invasive methods. Technical improvements made this measurement more accurate and feasible.

Our study revealed that ICT detected by echocardiography was prolonged in patients with CS when compared to the normal population. Left atrial size also increased in group 1. Although this study was not designed to detect silent AF episodes in the groups, increased conduction time and left atrial enlargement are known as AF triggers. One can only speculate that group 1 patients may have increased episodes of AF. This study shows that ICT calculated by echocardiography was prolonged in patients with CS. One electrophysiological study showed the increased atrial vulnerability in young stroke patients with atrial septal abnormalities (Berthet et al. 2000).

Silent AF episodes can easily be detected in patients with implanted devices either directly from interrogation of the device or via remote monitoring (Lima et al. 2015; Healey et al. 2013). The CRYSTAL AF study showed that AF was more frequently detected with insertable cardiac monitors than with conventional follow-up in patients with a recent CS. In that study, only age and prolonged $\mathrm{PR}$ interval at enrollment were associated with AF. Intrinsic PR prolongation has been consistently demonstrated to be associated with AF as it represents intrinsic atrial conduction disease (Sanna et al. 2014). In patients without a cardiac device, it is very difficult to detect 
AF episodes. Our study results may reflect a practical approach to overcome this difficulty.

In a recent study, the EMBRACE trial, premature atrial beats were found to be associated with silent episodes of AF in Holter recordings in patients with cryptogenic emboli (Gladstone et al. 2015). Prolonged ICT may be associated with left atrial mechanical remodeling and dysfunction, both of which may be substrates for thromboembolism in CS patients. Whether increased atrial premature beats, $\mathrm{p}$ wave dispersion or ICT increase the tendency to tromboemboli by possibly increased AF episodes or by some unknown subclinical atrial pathology unrelated with AF is yet to be demonstrated. Since there is no clinical data supporting the use of anticoagulation regarding the prolonged ICT, indication for anticoagulation should be based on current recommendations (Glotzer and Ziegler 2013).

\section{Limitations}

The number of subjects was too small to generalize the results. Although this study was not designed to reveal the relationship between PAF and ICT, it shows an association between ICT and stroke.

\section{Conclusions}

This study shows that ICT measured by echocardiography was prolonged in patients with CS. This technique can be applied widely and may lead clinicians to insist on monitoring patients to reveal silent AF. This is especially noteworthy if the presence of AF would likely change the current therapeutic approach and provide additional diagnostic tools for these particular patients.

\section{Methods}

A total of 285 consecutive patients diagnosed with cerebrovascular accident in our neurology clinic between April 2014 and January 2015 were investigated for possible CS. All patients were prospectively evaluated and regularly underwent clinical and instrumental evaluation. Patients had routine blood tests (i.e. full blood count, clotting, C-reactive protein, erythrocyte sedimentation rate, liver function, renal function, thyroid function, electrolytes, and lipid profile) after the stroke episode. Thrombophilia screening, vasculitis screening and genetic tests, where appropriate, were performed for patients with CS or those younger than 45 . We did not enroll 142 patients with stroke in whom the cause of stroke was identified initially. The remaining 143 patients with possible CS were considered for evaluation.

Of the 143 patients recruited for possible CS, 63 stroke/TIA patients (38 males; mean age $62 \pm 10$ years) who were considered to have cryptogenic stroke after extensive radiological and cardiac investigations constituted group 1. Eighty patients who had exclusion criteria were not included in the study. All cases were reviewed by two senior neurologists and stroke was classified according to the TOAST classification (Adams et al. 1993). The diagnosis of an ischaemic stroke was based on symptoms and signs of a sudden onset focal neurological deficit, lasting at least $24 \mathrm{~h}$, with corresponding findings on computerized tomography, magnetic resonance imaging scans. TIA was defined as a focal neurological deficit which resolved completely within $24 \mathrm{~h}$ without positive neurovascular imaging. We excluded patients with prior cerebrovascular accident, malignant arterial hypertension, uncontrolled diabetes mellitus, untreated hyperthyroidism, myocardial infarction or coronary bypass grafting history 1 month prior to stroke, valvular disease, documented history of AF or atrial flutter or presence of PFO. Patients with more than 3 days follow up in intensive care unit or requiring intubation due to respiratory failure were also excluded from the study.

Sixty-four patients (39 males; mean age $62 \pm 9$ years) with atypical symptoms admitted to cardiology clinics without any risk factor for cardiac disease and they were considered as healthy controls. Accordingly, they constituted group 2.

The echocardiography machine in the study provided real-time, simultaneous display of ECG and doppler echocardiogram of patients. Baseline echocardiography measurements recorded and compare with NORRE study (Kou et al. 2014). After the routine echocardiography evaluation, ICT was measured. The beginning of the P wave was marked in modified lead DI, in which the right arm electrode was attached on the top right of the manubrium and the left arm electrode in the fifth intercostal space at the right parasternal line (Lewis lead). The last atrial activity was marked as the top of the A wave trace which was obtained from the left atrium free wall next to the mitral annulus with tissue Doppler recording (Fig. 2).

This study was approved by our hospital review board and the informed consent was obtained from each patient.

Statistical analysis; age, gender, weight, height, echocardiographic parameters and ICT were compared between groups. Continuous variables are presented as mean $\pm \mathrm{SD}$, whereas dichotomous variables are described as numbers and percentages. The differences among the two groups were compared using the Chi-square test for categorical variables and Student's t tests or Mann Whitney U test for continuous variables. A cut point of ICT for predicting of CS was calculated by using receiver operating curve (ROC) analysis, and its sensitivity and specificity were estimated. Statistical analysis was performed by using the Statistical Package 


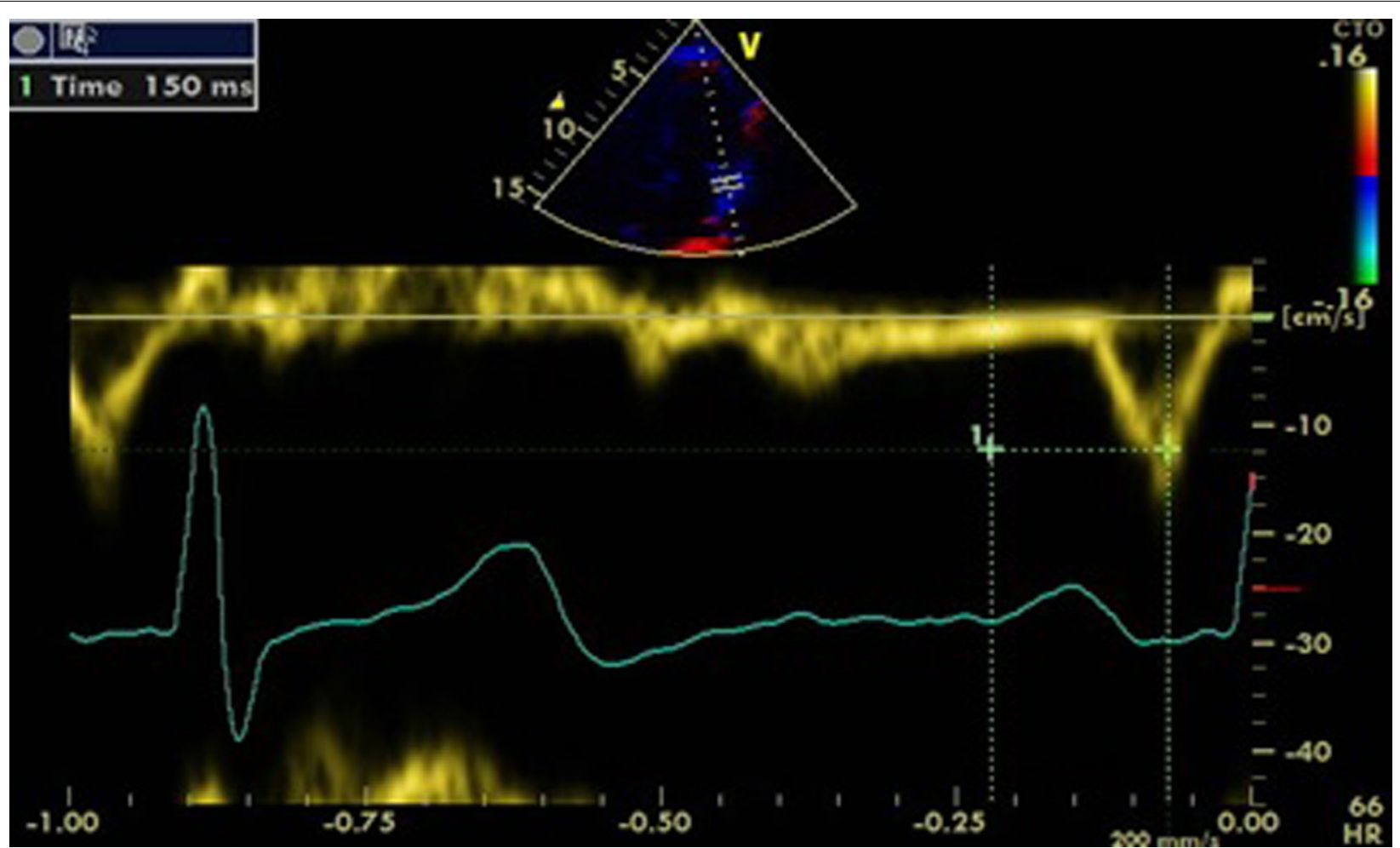

Fig. 2 Intraatrial conduction time is defined as the time between the beginning of the p wave in surface ECG and the top of the A wave recorded from the tissue Doppler imaging from the left atrial free wall next to the mitral annulus

for Social Sciences, version 16 (SPSS Inc., Chicago, IL, USA). A p value $<0.05$ was considered to indicate statistical significance.

\section{Abbreviations}

AF: atrial fibrillation; CS: cryptogenic stroke; TIA: transient ischemic attacks; ICT: intraatrial conduction time; TTE: transthoracic echocardiography; ROC: receiver operating curve.

\section{Authors' contributions}

MK have made substantial contributions to conception and design, or acquisition of data, made echocardiographic measurement, participated in the sequence alignment and drafted the manuscript. AK and MG find to patients and enrolled cryptogenic stroke to study. TK participated in the design of the study and performed the statistical analysis. DA participated in its design and coordination and helped to draft the manuscript. All authors read and approved the final manuscript.

\section{Author details}

${ }^{1}$ Atatürk Ĕ̆itim Araştırma Hastanesi Kardiyoloji Bölümü, Basın Sitesi 35150 Karabağlar, Izmir, Turkey. ${ }^{2}$ Medikalp Heart Disease Clinic Cardiology Department, Izmir, Turkey. ${ }^{3}$ Izmir Bozyaka State and Research Hospital Neurology Department, Izmir, Turkey.

\section{Acknowledgements}

We thank all members of EGEPOL hospital for helping us especially Dr. Nuri NASIR.

\section{Competing interests}

The authors declare that they have no competing interests.
Received: 5 January 2016 Accepted: 12 February 2016

Published online: 19 February 2016

\section{References}

Adams HP Jr, Bendixen BH, Kappelle LJ, Biller J, Love BB, Gordon DL, Marsh EE (1993) Classification of subtype of acute ischemic stroke. Definitions for use in a multicenter clinical trial.TOAST.Trial of Org 10172 in Acute Stroke Treatment. Stroke 24:35-41

Berthet K, Lavergne T, Cohen A, Guize L, Bousser MG, Le Heuzey JY, Amarenco P (2000) Significant associ-ation of atrial vulnerability with atrial septal abnormalities in young patients with ischemic stroke of unknown cause. Stroke 31:398-403

Cozma D, Mornos C, Pescariu S, Petrescu L, Lighezan D, Dragulescu SI (2006) Electrophysio-logical and echocardiographic parameters predisposing to atrialfibrillation in patients with a structurally normal heart. Kardiol Pol 64:143-150

Dogan U, Dogan EA, Tekinalp M, Tokgoz OS, Aribas A, Akilli H, Ozdemir K, Gok $H$, Yuruten B (2012) P-wave dispersion for predicting paroxysmal atrialfbrillation in acute ischemic stroke. Int J Med Sci 9:108-114

Fuenmayor AJ, Ramírez L, Fuenmayor AM (2002) Validation of inter-atrial conduction time measurement by means of echo-Doppler. Arch Cardio Mex 72:125-128

Gladstone DJ, Dorian P, Spring M, EMBRACE Steering Committee and Investigators (2015) Atrial premature beats predict atrial fibrillation in cryptogenic stroke: results from the EMBRACE trial. Stroke 46:936-941

Glotzer TV, Ziegler PD (2013) Silent atrial fibrillation as a stroke risk factor and anticoagulation indication. Can J Cardiol 29:14-23

Healey JS, Martin JL, Duncan A, Connolly SJ, Ha AH, Morillo CA, Nair GM, Eikelboom J, Divakaramenon S, Dokainish H (2013) Pacemaker-detected 
atrial fibrillation in patients with pacemakers: prevalence, predictors, and current use of oral anticoagulation. Can J Cardiol 29:224-228

Karaca M, Kinay O, Nazli C, Biceroglu S, Vatansever F, Ergene AO (2007) The time interval from the initiation of the P-wave to the start of left atrial appendage ejection flow: does it reflect interatrial conduction time? Echocardiography 24:810-815

Karaca M, Demirbas MI, Biceroglu S, Cevik A, Cetin Y, Arpaz M, Yilmaz H (2012) Prediction of early postoperative atrial fibrillation after cardiac surgery: is it possible? Cardiovasc J Afr 23:34-36

Kinay O, Nazli C, Ergene O, Dogan A, Gedikli O, Hoscan Y, Acar G, Altinbas A (2002) Time interval from the initiation of the electrocardiographic $P$ wave to the start of left atrial appendage ejection flow: a novel method for predicting atrial fibrillation recurrence. J Am Soc Echocardiogr 15:1479-1484

Kou S, Caballero L, Dulgheru R, Voilliot D, De Sousa C, Kacharava G, Athanassopoulos GD et al (2014) Echocardiographic reference ranges for normal cardiac chamber size: results from the NORRE study. Eur Heart J Cardiovasc Imaging 15:680-690
Lima C, Martinelli M, Peixoto GL, Siqueira SF, Wajngarten M, Silva RT, Costa R, Filho R, Ramires JA (2015) Silent atrial fibrillation in elderly pacemaker users: a randomized trial using home monitoring. Ann Noninvasive Electrocardiol, JA. doi:10.1111/anec.12294

Mohr JP (1988) Cryptogenic stroke. N Engl J Med 318:1197-1198

Sanna T, Diener HC, Passman RS, Crystal AF Steering Committee (2014) Cryptogenic stroke and atrial fibrillation. N Engl J Med 371:1259-1262

Villani GQ, Piepoli M, Rosi A, Capucci A (1996) P-wave dispersion index: a marker of patients with paroxysmal atrial fibrillation. Int J Cardiol 55:169-175

Wolf PA, Abbott RD, Kannel WB (1991) Atrial fibrillation as an independent risk factor for stroke: the Framingham Study. Stroke 22:983-988

\section{Submit your manuscript to a SpringerOpen ${ }^{\circ}$ journal and benefit from:}

- Convenient online submission

- Rigorous peer review

- Immediate publication on acceptance

- Open access: articles freely available online

- High visibility within the field

- Retaining the copyright to your article

Submit your next manuscript at $>$ springeropen.com 